doi http://dx.doi.org/10.18542/rmi.v15i24.10040

Margens: Revista Interdisciplinar | e-ISSN:1982-5374 | V. 15 | N. 24 | Jun, 2021, pp. 123-135.

\title{
MOVIMENTO DE MULHERES DO XINGU (MMX)
}

\section{XINGU WOMEN'S MOVEMENT (MMX)}

\author{
Joselaine Raquel da Silva PEREIRA (UNILA) ${ }^{1}$
}

Resumo: Este artigo trata sobre o Movimento de mulheres do Xingu (MMX) como uma forma de resistência das mulheres xinguanas contra diversas formas de violências interseccionais a que estão submetidas, apresentando-se como um movimento insurgente que busca ocupar os espaços de tomada de decisões dentro e fora de suas comunidades. Meu objetivo é demonstrar como seus discursos e ações estão alinhados com um projeto de sociedade mais equilibrada entre homens e mulheres e seres humanos e natureza (o bem viver), através de uma análise de diversos materiais audiovisuais em conjunto com uma revisão bibliográfica sobre temáticas de gênero e de ecologia, recorrendo ao uso de entrevistas e citações como métodos de exemplificação das cosmovisões e cosmo práticas das mulheres originárias, e por fim apresento essa práxis como um modelo de resistência coletiva inter epistemológica contra o "des-envolvimento" capitalista e individualista.

Palavras-chave: Mulheres indígenas. Território Indígena do Xingu. Resistências coletivas. Interepistemologias. Bem viver.

\begin{abstract}
This article deals with the Xingu Women's Movement (MMX) as a form of resistance by Xingu women against various forms of intersectional violence to which they are subjected, presenting itself as an insurgent movement that seeks to occupy the decision-making spaces within and outside their communities. My objective is to demonstrate how their speeches and actions are aligned with a project of a more balanced society between men and women and human beings and nature (the concept of good living), through an analysis of several audiovisual materials together with a bibliographic review on themes of gender and ecology, resorting to the use of interviews and quotations as methods of exemplifying the cosmovisions and cosmopractices of the original women, and finally I present this praxis as a model of collective interepistemological resistance against capitalist and individualistic "disinvolvement".
\end{abstract}

Keywords: Indigenous women. Indigenous territory of the Xingu. Collective resistances. Interepistemologies. Good living.

\footnotetext{
1 Mestranda no Programa de Pós-graduação Interdisciplinar em Estudos Latino-americanos (PPGIELA) pela Universidade Federal da Integração Latino-americana (UNILA), e Bacharel em Antropologia - Diversidade Cultural Latino-americana, pela mesma universidade.E-mail: jopereira.sm@gmail.com
} 


\section{INTRODUÇÃO}

\subsection{A constituição do MMX}

O Movimento de Mulheres do Xingu (MMX) é um exemplo de autonomia coletiva feminina e resistência às diversas formas de violências interseccionais às quais as mulheres indígenas estão expostas, são elas violência de gênero, raça, classe, além de discriminação linguística e cultural. As mulheres pertencentes a este coletivo se organizam em redes que as conectam apesar das distâncias físicas e das diferenças culturais, já que o Parque Indígena do Xingu (PIX) reúne cerca de 8 mil indivíduos de 16 povos distintos, cada um com suas próprias tradições ancestrais, em um território de cerca de 2,8 milhões de hectares. O parque é considerado área demarcada desde o ano de 1961, possuindo um total de 2,8 milhões de hectares no norte do Mato Grosso.

O movimento das mulheres é todas as etnias do Xingu né, que é... Vou começar pelo rio, descendo o rio: Kalapalo, Kuikuro, Nafukuá, Matipu, Mehinako, Aweti, Yawalapiti, Waurá, Kamayurá, Trumai, mulheres Ikpeng, Kawaiweté, Yudjá, Naruvotu, Kisedje. O movimento é esse, é as ações dessas mulheres, é as xinguanas como um todo né. (YAWALAPITI, Watatakalu. 2019) ${ }^{2}$

Como pode-se observar no discurso de Watatakalu Yawalapiti (2019), o movimento é muito diverso e essa união permite que as mulheres se organizem em prol de causas como os direitos das mulheres e dos povos das florestas, e contra a destruição da natureza pelo agronegócio, pelos madeireiros ou garimpeiros. Anna Terra Yawalapiti também comenta sobre os objetivos do movimento, no documentário "Mulheres do Xingu" (2019):

São vários pensamentos diferentes de cada mulher, de cada liderança né, é aquilo que eu falei, tem mulheres que é do movimento que luta pela preservação da cultura, tem mulher que luta pela preservação da cultura do seu alimento né, o plantio tradicional, tem mulher que luta pela voz das mulheres, tem mulher que luta pela... pela política né, fora né, do nosso território, então são vários, então isso aí né, nós unimos sabe, nós unimos dali, dali, dali e a gente fez uma coisa só. E a gente viu que a nossa fala é uma direção só, não é uma coisa diferente. (YAWALAPITI, Anna Terra. 2019) ${ }^{3}$

\footnotetext{
${ }^{2}$ Informação oral, transcrição nossa. Original disponível em: https://www.youtube.com/watch?v=BqjIat5WrA4\&ab_channel=LaranjeirasCinema . Acesso em 21 de fev. de 2021. ${ }^{3}$ Informação oral, transcrição nossa. Original disponível em: https://www.youtube.com/watch?v=BqjIat5WrA4\&ab_channel=LaranjeirasCinema . Acesso em 21 de fev. de 2021.
} 


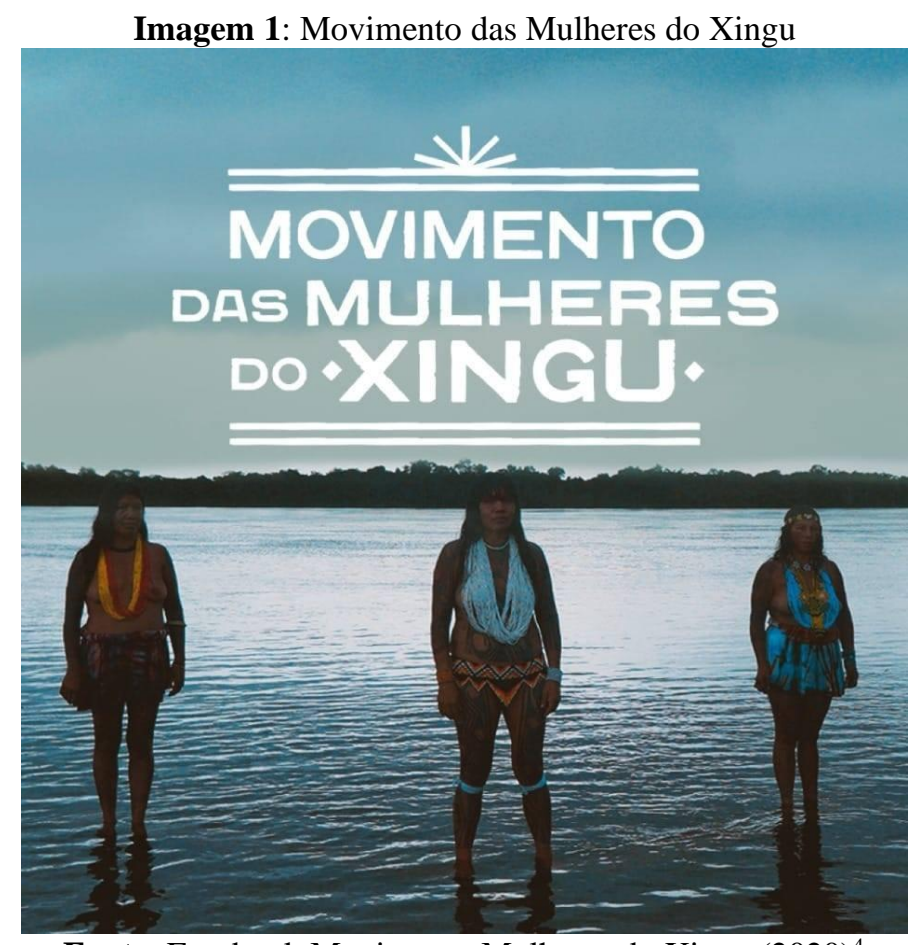

Fonte: Facebook Movimento Mulheres do Xingu (2020) ${ }^{4}$

\subsection{As ações do movimento}

Desde 2017 a população xinguana organiza o território a partir de diversos projetos de autogestão protagonizado pelos próprios povos, e alguns deles dos quais as mulheres do MMX participam são a plantação de pequi para produção de óleo pelas mulheres Kisêdjê, a produção e comercialização de pimentas tradicionais da região pelas mulheres Wauja e a coleta de sementes nativas pelas mulheres Ikpeng, conhecidas como Yarang (mulheres formigas) para a reflorestação de áreas desmatadas. Todas elas são iniciativas das próprias mulheres que propõem maneiras de organização e mobilização coletiva não hierárquicas em prol de toda a comunidade e da preservação e restauração da própria natureza.

Entre os dias 24 e 26 de abril de 2019 as mulheres do MMX participaram do $15^{\circ}$ Acampamento Terra Livre (ATL) em Brasília (DF), onde conquistaram algumas de suas reivindicações como a desistência do desmantelamento da Secretaria de Saúde Indígena (SESAI) e a recuperação do direito da Fundação Nacional do Índio (Funai) demarcar territórios indígenas. Durante o ATL também ocorreu a estreia do filme-manifesto "Gigantes pela própria natureza", dirigido por João Unzer e Rogo de Castro, que foi filmado com o intuito de retratar a realidade das mulheres xinguanas e pedir o apoio da sociedade em geral nessa luta.

${ }^{4}$ Imagem de identificação do coletivo na rede social. Disponível em:

https://www.facebook.com/mulherxingu/photos/a.2374737742758981/2707242912841794/? tn $\quad=\% 3 \mathrm{C}$ 
Em seguida, as mulheres xinguanas criaram o Departamento de Mulheres Indígenas da Associação Terra Indígena Xingu (ATIX), liderado por Watatakalu Yawalapiti e Amairé Kaiabi Suiá e em maio de 2019 ocorreu o primeiro grande Encontro das mulheres do Xingu, onde se reuniram mais de 200 mulheres de 16 etnias na aldeia Ilha Grande (MT) para debater diversos assuntos relacionados à preservação dos territórios ancestrais e aos direitos de participação política das mulheres.

Entre os dias 9 e 13 de agosto de 2019 também aconteceu a $1^{\text {a }}$ Marcha das mulheres indígenas, com a temática "Território: nosso corpo, nosso espírito", reiterando a união entre os corpos e os territórios femininos (corpos-territórios) ${ }^{5}$, organizada e protagonizada por elas mesmas, reunindo cerca de 2.500 indivíduos de 130 povos pelas mesmas pautas de luta, e no dia 14 se juntaram à Marcha das Margaridas, que acontece a cada 4 anos em Brasília, protagonizada pelas mulheres do campo, das florestas e das águas de todo o Brasil, se engajando em uma luta cada vez mais ampla e inclusiva.

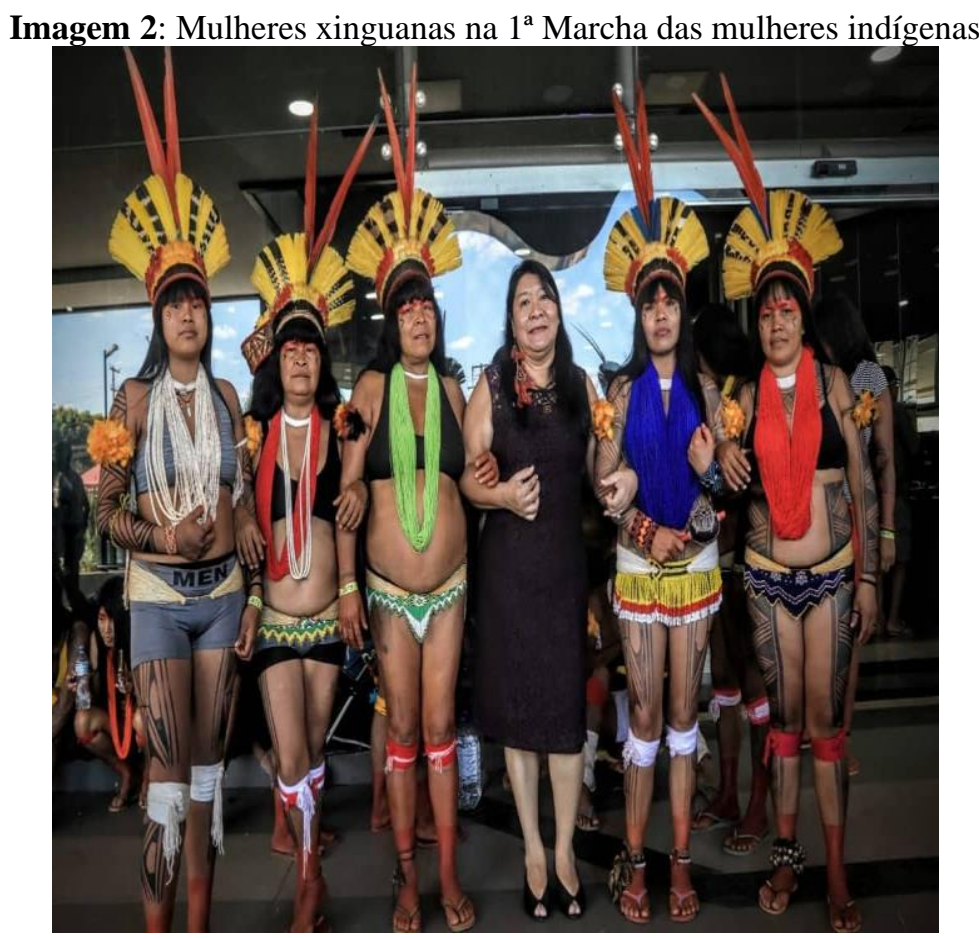

Fonte: Facebook, Joênia Wapichana $(2019)^{6}$

Ao final do evento as mulheres indígenas redigiram um documento denominado "O território é nossa vida" (2019), onde afirmaram o seguinte:

A Marcha das Mulheres Indígenas foi pensada como um processo, iniciado em 2015,

\footnotetext{
${ }^{5}$ Categoria criada pelas mulheres do Feminismo Comunitário da Guatemala, que marca uma indiferenciação entre os corpos das mulheres e a terra-território.

${ }^{6}$ Imagem disponível em

https://www.facebook.com/Dep.Joeniawapichana/photos/a.278004339463930/432974130633616/.
} 
de formação e empoderamento das mulheres indígenas. Ao longo desses anos dialogamos com mulheres de diversos movimentos e nos demos conta de que nosso movimento possui uma especificidade que gostaríamos que fosse compreendida. $\mathrm{O}$ movimento produzido por nossa dança de luta, considera a necessidade do retorno à complementaridade entre o feminino e o masculino, sem, no entanto, conferir uma essência para o homem e para a mulher. [...] o intuito é exatamente contrapor, problematizar e trazer reflexões críticas a respeito de práticas cotidianas e formas de organização política contemporâneas entre nós. Precisamos dialogar e fortalecer a potência das mulheres indígenas, retomando nossos valores e memórias matriarcais para podermos avançar nos nossos pleitos sociais relacionados aos nossos territórios. (BRASIL DE FATO, 2019)

Por conta da pandemia do novo coronavírus e da dificuldade de se reunirem fisicamente, durante o ano de 2020 as mulheres do movimento participaram de diversas atividades virtuais, realizaram diversas lives na página do Facebook do Movimento das Mulheres do Xingu, como a live denominada "As queimadas no Xingu e os impactos na saúde em tempos de pandemia de coronavírus", participaram da live "Mulheres indígenas: A sabedoria ancestral do bem viver", promovida pela Rede de apoio a mulheres agroflorestoras, e também da "A cura do universo através dos cantos ancestrais das mulheres indígenas", no dia 22 de abril, e "Mulheres indígenas: o sagrado da existência e a cura da terra", promovida pela Articulação dos Povos Indígenas do Brasil (APIB) nos dias 7 e 8 de agosto.

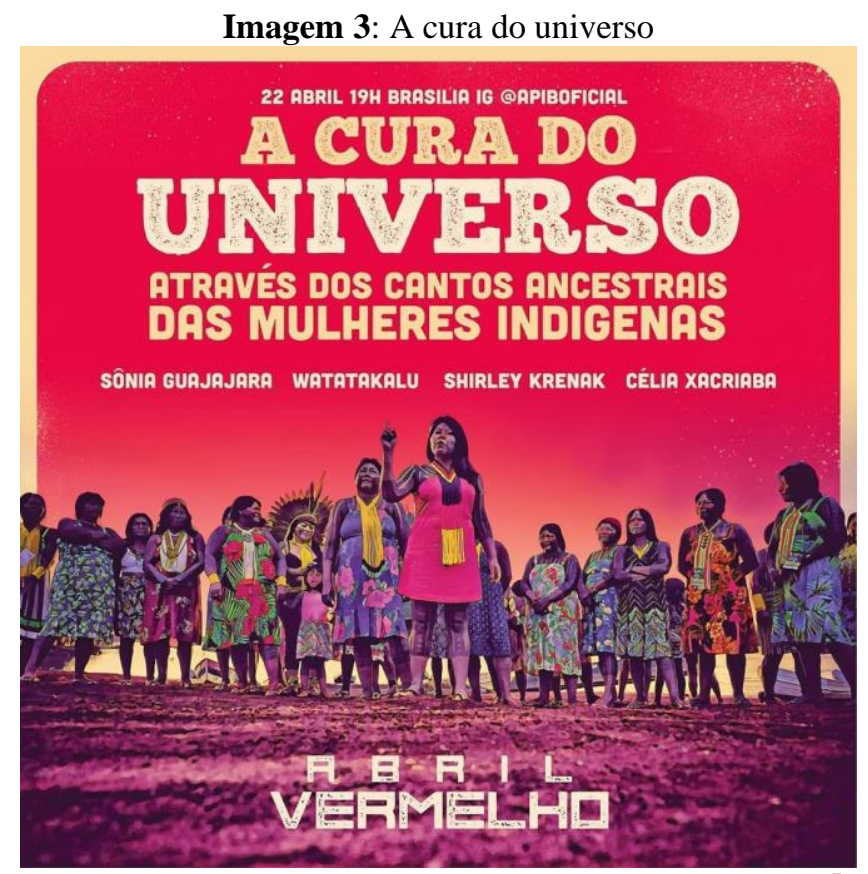

Fonte: Facebook, Movimento Mulheres do Xingu (2020) ${ }^{7}$

\footnotetext{
${ }^{7}$ Imagem alusiva ao abril vermelho. Disponível em: https://scontent.fopo2-2.fna.fbcdn.net/v/t1.64359/p843x403/94404261 2714864262079659 7745293332955267072 n.jpg? nc cat $=108 \& \mathrm{ccb}=1-$ 3\& nc sid=9267fe\& nc eui2=AeECz4W 9K3Pdfwhrr7iWnzSBUq0fEjzpEMFSrR8SPOkQ9V4pTn4chrYwMNcnrSd ySv_cFa6j_3kuUPsMrW4BC8p\&_nc ohc=PRLOYpHwyssAX9y5zxj\&_nc ht=scontent.fopo22.fna\&oh $=\bar{d} 7 \mathrm{e} 9 \mathrm{f} 4 \mathrm{f} 78 \mathrm{c} 2309 \mathrm{ae} 1 \mathrm{fd} 4 \mathrm{a} 80 \mathrm{fd} 773051 \mathrm{a} \& \mathrm{ee}=60 \mathrm{~F} 93 \mathrm{~F} 5 \mathrm{~B}$
} 
Além disso participaram em diversos eventos on-line a nível nacional e internacional, como o “Acampamento Terra Livre Online" que aconteceu durante os dias 27 a 30 de abril de 2020, e o "Cura da terra: Encontro global de mulheres indígenas" que ocorreu no dia 5 de setembro de 2020, considerado o dia internacional das mulheres indígenas e reuniu mulheres de diversos países do mundo para tratar de temas relacionados à sustentabilidade e suas práticas e propostas para a cura da Mãe Terra.

Imagem 4: Mulheres indígenas: cura da terra

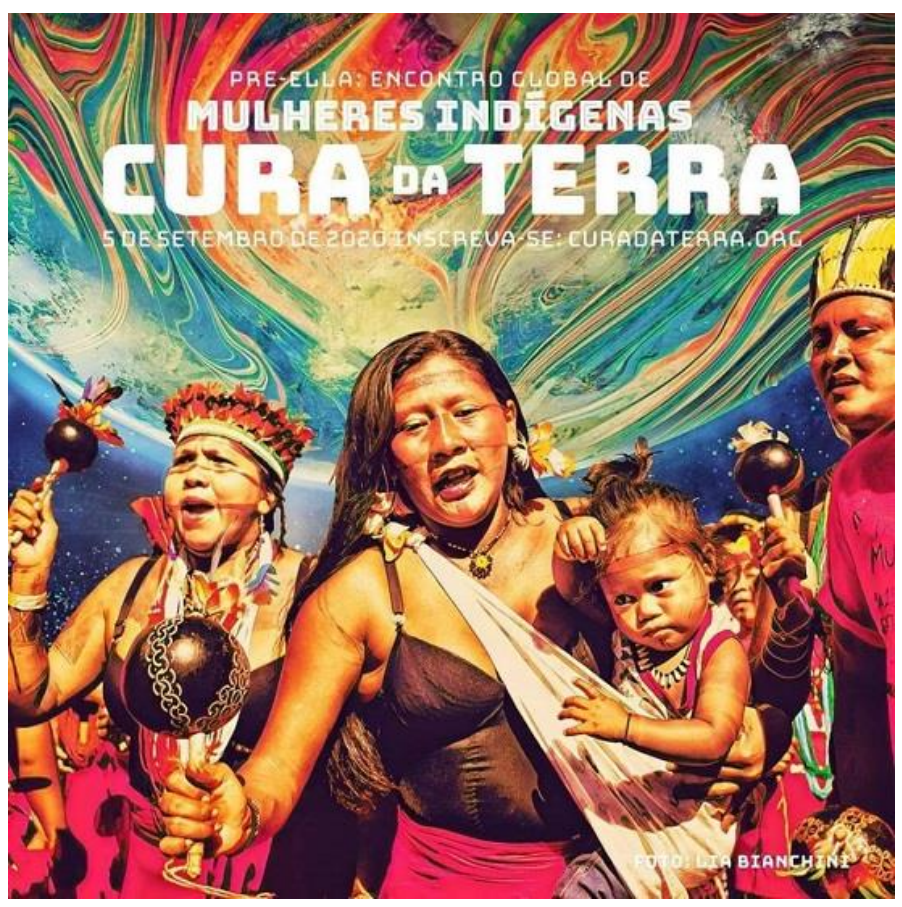

Fonte: CEDEFES, Lia Bianchini, $(2020)^{8}$

O MMX em parceria com a Associação Terra Indígena Xingu (ATIX) também promoveu uma vaquinha online com a meta de $\mathrm{R} \$ 150.000,00$ para a aquisição de alimentos, itens de higienização e outros materiais necessários para distribuição nas 4 regiões do Xingu durante a pandemia de COVID19, já que os povos indígenas no geral ficaram fragilizados pela falta de assistência governamental, aliada ao congelamento do turismo que trouxe mais instabilidade econômica nos territórios.

${ }^{8}$ Imagem alusiva ao encontro "Pré-ellas: Encontrão global mulheres indígenas: cura da terra". Disponível em: https://www.cedefes.org.br/eventos/mulheres-indigenas-cura-da-terra/ 


\section{DESENVOLVIMENTO}

\subsection{Os principais desafios}

Elizangela Baré (MULHERES DO XINGU, 2019) aponta os principais empecilhos que o

MMX e os Movimentos Indígenas em geral enfrentam atualmente:

Principal ameaça que nós tamos sofrendo hoje é o próprio governo né, o governo falar pra nós que nosso território que foram demarcado, eles vão rever essas demarcação das terras, já são pouca terra, se eles vão diminuir mais, e aí, pra onde que nós indígenas vamos? Aí que o planeta vai ficar mais doente, até eles vão ficar doente né. (MULHERES DO XINGU, 2019) ${ }^{9}$

Elizangela se refere às implicações do Marco Temporal, que propõe que para que uma terra indígena seja demarcada, os povos que a reclamam deveriam estar ocupando esse território antes de 5 de outubro de 1988, data da promulgação da Constituição Cidadã, o que gerou diversas problemáticas decorrentes, pois muitos povos indígenas nesse então já haviam sido expulsos de suas terras ancestrais por fazendeiros, latifundiários, etc. Até a presente data ainda não foi tomada nenhuma decisão do Supremo Tribunal Federal sobre o marco, e enquanto isso os invasores dos territórios tradicionais seguem usufruindo das terras e dos bens naturais roubados.

Os vizinhos ruralistas desmatam, desmatam e desmatam o entorno, e tão tirando toda a floresta né, então a gente só tem isso aqui que ainda é... que mantém, mas que ainda, nossas terras, é muito pouco espaço de floresta que tem pra poder, poder dar ar fresco né, poder fazer todo o processo natural dele, num tamanho do desmatamento que já tem né. (MULHERES DO XINGU, 2019) ${ }^{10}$

Também fica evidente o descontentamento com os altos índices de desmatamento da região, que é um dos fatores que coloca em risco a manutenção dos modos de vida tradicionais dos povos originários, além da degradação do meio ambiente, segundo a Revista Marie Claire (2019) mais de 40\% da mata nativa das nascentes do Rio Xingu foi destruída pelo agronegócio nos últimos 20 anos, e segundo o Sirad-X, um sistema de monitoramento de desmatamento da Rede Xingu+, somente entre julho e agosto de 2019, 14,7 mil hectares foram desmatados (172\% a mais que o mesmo período de 2018).

\footnotetext{
${ }^{9}$ Transcrição nossa da fala de Elizangela Baré. Original disponível em:

https://www.youtube.com/watch?v=BqjIat5WrA4\&ab channel=LaranjeirasCinema . Acesso em 21 de fev. de 2021.

10 Transcrição nossa da fala de Watatakalu Yawalapiti. Original disponível em:

https://www.youtube.com/watch?v=BqjIat5WrA4\&ab_channel=LaranjeirasCinema . Acesso em 21 de fev. de 2021.
} 
Além disso, o TIX foi o território indígena brasileiro que mais sofreu com as queimadas e incêndios florestais criminosos no ano de 2020, sendo que de acordo com o Instituto Centro de Vida (ICV) e o Instituto Nacional de Pesquisas Espaciais (Inpe), entre janeiro e setembro deste ano foram detectados 102.918 hectares incendiados, superando em $155 \%$ o mesmo período do ano anterior. Os xinguanos e as xinguanas foram afetados gravemente tanto pela pandemia de COVID-19, quanto pelos desmatamentos que agravaram ainda mais o alastramento dos incêndios, sendo que a fumaça dos incêndios também prejudicava a respiração dos enfermos do novo coronavírus, além de queimar várias casas com os pertences da população e deixar diversos mortos e feridos, se tornando assim um ciclo de danos materiais e imateriais aos moradores e às florestas.

\subsection{As epistemologias e interepistemologias}

As cosmovisões e cosmopráticas das mulheres do MMX constituem uma mescla das diversas culturas existentes na região do Rio Xingu, mas as principais epistemologias que podemos observar como práxis do movimento são a importância das ações coletivas, a defesa do território e a integração dos seres humanos à natureza, sendo que as 3 são indissociáveis.

A importância da coletividade fica evidente em algumas falas das entrevistas a seguir: "Seja com a comercialização de sementes, artesanato, pimenta, sal de aguapé ou pequi, o objetivo é o fortalecimento das mulheres" (MULHERES DO XINGU, 2019) "11 " "O nosso propósito do movimento é isso né, unir as mulheres pra a gente poder discutir sobre os assuntos que interessam pra a gente né!?” (MULHERES DO XINGU, 2019)12 e "Viemos para conversar, trocar ideias. É uma atividade coletiva, de união das mulheres. A gente incentiva, ensina os conhecimentos sobre sementes para os jovens" (MULHERES DO XINGU, 2019) ${ }^{13}$.

Então não tem como falar da defesa do território, não tem como falar dos direitos indígenas, não tem como falar da sustentabilidade, não tem como falar da política do movimento indígena sem a presença das mulheres, elas precisam participar, elas precisam estar lá para contribuir, ajudar o fortalecimento do movimento indígena em defesa dos territórios e defesa do direito. (MULHERES DO XINGU, 2019) ${ }^{14}$

\footnotetext{
11 Transcrição nossa da fala de Watatakalu Yawalapiti. Original disponível em:
}

https://www.youtube.com/watch?v=BqjIat5WrA4\&ab channel=LaranjeirasCinema . Acesso em 21 de fev. de 2021.

12 Transcrição nossa da fala de Iré Kayabi. Original disponível em:

https://www.youtube.com/watch?v=BqjIat5WrA4\&ab_channel=LaranjeirasCinema . Acesso em 21 de fev. de 2021.

13 Transcrição nossa da fala de Koré Ikpeng. Original disponível em:

https://www.youtube.com/watch?v=BqjIat5WrA4\&ab channel=LaranjeirasCinema . Acesso em 21 de fev. de 2021.

${ }_{14}$ Transcrição nossa da fala de Elizangela Baré. Original disponível em:

https://www.youtube.com/watch?v=BqjIat5WrA4\&ab_channel=LaranjeirasCinema . Acesso em 21 de fev. de 2021. 
No apontamento de Elizangela já é possível encontrar uma conexão dos 3 pontos referidos, ou seja, a comunidade, o território e a natureza, e a importância da participação feminina nos processos de resistência dentro e fora da comunidade, estando presentes nos espaços coletivos de construção e desconstrução. É fundamental destacar que as mulheres do MMX, assim como grande parte das mulheres indígenas não se identificam com o termo "feminista", pois buscam participação igualitária nos debates e nas ações políticas juntamente com os homens, caminhando ao lado deles para a construção de modos de vida mais harmônicos para todas e todos. Esse pensamento é explicado por Francesca Gargallo (2014):

[Son] mujeres que buscan una buena vida para las mujeres de su pueblo en relación con los hombres de su pueblo. Su principal lugar de identificación para la acción política, cultural, educativa se halla en grupos mixtos cuyos miembros, más allá del género, comparten una fuerte discriminación u opresión racista por parte del estado nacional y por las mujeres y hombres blancos y blanquizados. Las mujeres indigenas que se niegan a decirse y a que se les llame feministas, pero actúan en favor de las mujeres de su comunidad, rechazan la ubicación en la cultura hegemónica del feminismo como movimiento político. Son casi todas dirigentes de un movimiento político o cultural que hace de la identidad uno de los ejes de su acción política, junto con la reivindicación de la tierra y una ley y una educación propias. (GARGALLO, 2014, p. 125) $)^{15}$

Na declaração de Anna Terra também se apresenta a estima pela defesa do território: “[...] Porque a gente não pensa vender madeira, vender uma parte da terra pra conseguir dinheiro, a gente tem tanta coisa pra a gente conseguir apoio que a gente não precisa destruir nada.” (YAWALAPITI, A., 2019) ${ }^{16}$. Ela reafirma um dos propósitos dos povos indígenas, que é o de proteger a terra e seus bens naturais, e impedir a destruição de ambos pelo agronegócio, pelos madeireiros ou garimpeiros e outros.

As mulheres Yarang também representam o trabalho coletivo das formiguinhas ao mesmo tempo em que demonstram sua preocupação pelo desmatamento através do plantio das sementes nativas coletadas por meio de articulação coletiva, a renda obtida com a comercialização do excedente

\footnotetext{
15 Tradução nossa: [São] mulheres que buscam uma boa vida para as mulheres de seu povo em relação com os homens de seu povo. Seu principal lugar de identificação para a ação política, cultural, educativa se encontra em grupos mistos cujos membros, para além allá do gênero, compartilham uma forte discriminação ou opressão racista por parte do estado nacional e pelas mulheres e homens brancos e branquizados. As mulheres indigenas que se negam a dizer que são feministas e a que as chamem de feministas, mas agem a favor das mulheres de sua comunidade, rechaçam esse lugar na cultura hegemônica do feminismo como movimento político. São quase todas dirigentes de um movimento político ou cultural que faz da identidade um dos eixos de sua ação política, junto com a reivindicação da terra e uma lei e uma educação próprias. (GARGALLO, 2014, p. 125)

16 Transcrição nossa da fala de Anna Terra Yawalapiti. Original disponível em:

https://www.youtube.com/watch?v=BqjIat5WrA4\&ab channel=LaranjeirasCinema . Acesso em 21 de fev. de 2021. 
de sementes se transforma em investimentos coletivos para o bem viver ${ }^{17}$ das comunidades. Na letra traduzida da seguinte canção podemos observar novamente o significado tão potente da coletividade e do equilíbrio com a natureza presente nos territórios:

\author{
Cantar, beneficiar, armazenar \\ Vamos convidar as pessoas para ver nosso plantio \\ Venham ver nosso plantio \\ Sempre animadas, as mais adoradas \\ Arayó \\ Venham ver nosso plantio. \\ (SOCIOAMBIENTAL, 2019) ${ }^{18}$
}

Na letra da canção, assim como em diversos outros discursos ao longo deste artigo podemos observar uma recorrente preocupação pela manutenção da memória ancestral e a transmissão desses saberes aos mais jovens, sendo estes saberes transpassados de geração em geração, que unem aspectos da natureza com a ação humana baseada em cada cultura, - sobre a diversidade biológica em conjunto com a diversidade cultural presente nos territórios -, isto é o que Narciso Boassols-Barrera \& Víctor M. Toledo (2015) chamam de "memória biocultural".

Também fica clara a cosmovisão presente no movimento de que a natureza e as comunidades são um só e que para viver bem é necessário que haja um equilíbrio entre toda a vida na Terra, por esse motivo é que as mulheres se recusam a derrubar árvores para trocá-las por recursos financeiros e se esforçam tanto para reflorestar as nascentes do Rio Xingu. Esse pensamento se opõe ao desenvolvimento capitalista contemporâneo e coincide com as perspectivas de Jacques Mick \& Noa Cykman (2020):

Não cabe falar em políticas de des-envolvimento - que é, afinal, um desentrelaçamento, um distanciar-se da natureza. Ao contrário, as experiências utópicas que examinamos nos convidam a uma política de envolvimento, um entrelaçar-se, mergulhar de volta na vida, reativar o parentesco entre as formas vivas. A sobrevivência depende da dilatação da identidade, do exercício de uma nova subjetividade, mais vasta que a humana, mais antiga do que a moderna, e mais bem enraizada (embora "nova" para nós). Uma subjetividade ciente da natureza de que é feita, que a iguala e a aproxima de tudo ao seu redor. (CYKMAN \& MICK, 2020, p. 82)

\title{
CONCLUSÃO
}

As epistemologias que consistem o pensamento e a ação do MMC são fundamentalmente anti

${ }^{17} \mathrm{O}$ conceito de bem viver (Sumak Kawsay) tem origem no mundo indígena andino e se refere à cosmovisão de uma existência harmônica e equilibrada entre seres humanos e natureza.

${ }^{18}$ Disponível em: https://socioambiental.medium.com/elas-nunca-vão-andar-sozinhas-79e08853f35c 
"des-envolvimento", no sentido de valorizar as subjetividades e o envolvimento das comunidades com o território e a natureza que o compõe, criticando a ciência desenvolvimentista e progressista que se diz objetiva enquanto se baseia em uma única subjetividade, que propõe a divisão entre humanidade e natureza e a dominação da primeira sobre a segunda, para o benefício e a comodidade de seletos grupos da elite capitalista.

O movimento também cultiva os valores de coletividade e apoio entre as mulheres e entre os povos, a proteção da natureza e dos corpos-territórios, além disso, suas ações também levam em consideração a memória biocultural de cada povo, trazendo sempre a contribuição dos e das ancestrais, constituindo uma luta diversamente unificada e muito mais potente que as lutas isoladas, pois sua potência está na sabedoria ancestral feminina: o cuidado da terra, das sementes e dos corposterritórios, a reprodução da vida e dos modos de viver.

Essas cosmovisões e cosmopráticas se tornam assim um exemplo de resistência a ser seguido, na medida em que a sociedade em geral precisa lidar com crises climáticas, destruição das florestas e poluição dos rios e oceanos, a fome, a desigualdade social, a exploração de trabalhadores e trabalhadoras, entre outros problemas criados pelos próprios seres humanos e suas ideologias capitalistas desenvolvimentistas, e que os povos tradicionais e principalmente as mulheres possuem a resposta para a recuperação dos biomas, a preservação dos bens naturais e a cura da Mãe Terra: o bem viver, uma existência equilibrada e respeitosa entre seres humanos e natureza.

\section{REFERÊNCIAS}

\#MATILDA.MY | Gigantes no ATL: Realização: Movimento de Mulheres do Xingu; Matilda.my. Brasília. 2019. Disponível em: https://www.youtube.com/watch?v= Cx0QtKHvVRY \& ab_channel=MatildaMy. Acesso em 25 de fev. de 2021.

AMAZÔNIA REAL. Amazônia em chamas 20: Xingu é o território indígena com mais focos de queimadas no Brasil. Amazônia Real. 2020. Disponível em: https://amazoniareal.com.br/amazoniaem-chamas-20-xingu-e-o-territorio-indigena-com-mais-focos-de-queimadas-no-brasil-18-09-2020/. Acesso em: 10 de mar. de 2021.

BASSOLS-BARRERA, Narciso \& TOLEDO, Víctor M. A memória biocultural: A importância ecológica das sabedorias tradicionais. Editora Expressão Popular. São Paulo. 2015.

BRASIL DE FATO. Marcha das mulheres indígenas divulga documento final: "O território é nossa vida". Brasil de fato. 2019. Disponível em: https://www.brasildefato.com.br/2019/08/15/mulheresindigenas-o-territorio-e-nossa-vida-nosso-corpo-e-nosso-espirito/. Acesso em: 05 mar. 2021.

BRASIL MONGABAY. Mulheres do Xingu se unem contra ameaças do governo Bolsonaro. 
Mongabay. 2019. Disponível em: https://brasil.mongabay.com/2019/12/mulheres-do-xingu-seunem-contra-ameacas-do-governo-bolsonaro/. Acesso em: 10 de mar. de 2021.

CEFEDES. Mulheres indígenas: cura da terra. CEFEDES. 2020. Disponível em: https://www.cedefes.org.br/eventos/mulheres-indigenas-cura-da-terra/. Acesso em: 10 de mar. de 2021.

CYKMAN, Noa \& MICK, Jacques. Para escapar à extinção: experiências de conexão humanonatureza em encontros Rainbow. In: Epistemologias do Sul: Pensamento Social e Político em/desde/para América Latina, Caribe, África e Ásia. Dossiê: Corpos e sujeitos na/da modernidade. Volume 4, número 1, 2020.

REVISTA MARIE CLAIRE. As histórias das mulheres líderes do território Xingu. Revista Marie Claire. 2019. Disponível em: https://revistamarieclaire.globo.com/Mulheres-doMundo/noticia/2019/08/historias-das-mulheres-lideres-do-territorio-xingu.html. Acesso em: 06 mar. 2021.

GARGALlO, Francesca. Feminismos desde Abya Yala: ideas y proposiciones de las mujeres de 607 pueblos en nuestra América. Ciudad de México: Editorial Corde y Confección. 2014.

GRANDES NOMES DA PROPAGANDA. Movimento Mulheres do Xingu ganha filme-manifesto. Grandes nomes da propaganda. 2019. Disponível em: https://grandesnomesdapropaganda.com.br/produtora/movimento-mulheres-do-xingu-ganha-filmemanifesto/. Acesso em: 05 mar. 2021.

JÔENIA WAPICHANA. Facebook. 2019. Disponível em: https://www.facebook.com/Dep.Joeniawapichana/photos/a.278004339463930/432974130633616/. Acesso em: 10 de mar. de 2021.

MULHERES DO XINGU. Laranjeiras Cinema e Cultura. Realização: Rainforest Journalism Found; Pulitzer Center. Produção: Maria Fernanda Ribeiro. Parque Indígena do Xingu. Cores, Vídeo MP4, Duração: 12min33seg.. $2019 . \quad$ Disponível em: https://www.youtube.com/watch?v=BqjIat5WrA4\&ab_channel=LaranjeirasCinema. Acesso em 25 de fev. de 2021.

MOVIMENTO MULHERES DO XINGU. Facebook. 2020. Disponível em: https://www.facebook.com/mulherxingu/photos/a.2374752716090817/2839547642944653/. Acesso em: 10 de mar. de 2021.

SOCIOAMBIENTAL. Elas podem curar o mundo. Instituto Socioambiental. 2019. Disponível em: https://www.socioambiental.org/pt-br/noticias-socioambientais/elas-podem-curar-o-mundo. Acesso em: 10 de mar. de 2021.

SOCIOAMBIENTAL. Parque indígena do Xingu comemora 57 anos. Instituto Socioambiental. 2018. Disponível em: https://www.socioambiental.org/pt-br/blog/blog-do-xingu/parque-indigenado-xingu-comemora-57-anos. Acesso em: 10 de mar. de 2021.

VAKINHA. Apoie os povos do Território Indígena do Xingu contra a Covid-19. Vakinha. 2020. 
Disponível em: https://www.vakinha.com.br/vaquinha/apoie-os-povos-do-territorio-indigena-doxingu-contra-a-covid-19?fbclid=IwAR3nvxiOIQpeFP-xjGH6ypmMKTfKX4rmVmyekj8vBvFykaMUMhjjIkczVA. Acesso em: 10 de mar. de 2021. 